\title{
Presentation of signet ring cell type at carcinoma ventriculi of the patient aged 20 years old ${ }^{*}$
}

\author{
Afrim Avdaj $^{1}$, Ugur Gozalan ${ }^{2}$, Nexhmi Hyseni $^{3 \#}$, Hatim Baxhaku ${ }^{1}$, Sherif Krasniqi ${ }^{1}$, \\ Shpejtim Rramanaj ${ }^{1}$ \\ ${ }^{1}$ Division of Surgery, Regional Hospital "Primarius Daut Mustafa", Prizren, Kosova; \\ avdajafrim@yahoo.com, hatimbaxhaku@hotmail.com, oni pz@hotmail.com, shpejtim@libero.it \\ ${ }^{2}$ American Hospital, Pristina, Kosovo; ugur.gozalan@spitliamerikan.com \\ ${ }^{3}$ Department of Pediatric Surgery, University Clinical Center, Prishtina, Kosovo; ${ }^{\#}$ Corresponding Author: nexhmi_h@yahoo.com
}

Received 1 July 2013; revised 4 August 2013; accepted 11 August 2013

Copyright (C) 2013 Afrim Avdaj et al. This is an open access article distributed under the Creative Commons Attribution License, which permits unrestricted use, distribution, and reproduction in any medium, provided the original work is properly cited.

\section{ABSTRACT}

Introduction: Diffuse variant of GC is composed of gastric-type mucous cells, which generally do not form glands, but rather permit the mucosa and wall as scattered individual cells or small clusters in an "infiltrative" growth pattern. These cells appear to arise from the middle layer of the mucosa, and the presence of intestinal metaplasia is not a prerequisite. In this version, mucin formation expands the malignant cells and pushes the nucleus to the periphery, creating a "signet ring" conformation. If the signetring cells are more than $50 \%$ of the tumor, the tumor is classified as signetring cell carcinoma [1]. This case is important for reporting because we encountered for the first time such a carcinoma type, due to the new age and its atypical presentation. Case Presentation: We report a case of a 20 years Albanian old patient with Signet Ring Cell Type of Gastric CA. The patient was brought at the urgency with severe abdominal pain, nausea and peritoneal irritation. Clinical examination has been made in emergency, where we conclude the signs of peritoneal irritation, from native Ro no signs of pneumoperitoneum, while laboratory tests found a slight anemia (erythrocytes 3.36, HCT 25, HGB 8.6). Two hours later we repeated the native RTG and there were present the signs of pneumoperitoneum. It was indicated urgent surgical in-

\footnotetext{
*Competing interests: The authors declare that they have no competing interests.

Contributions of authors: Our patient was admitted under the care of SHK, with the contribution of $\mathrm{HB}$, was treated. The main contributors to this manuscript are all authors who have approved the final manuscript.
}

tervention. Intraoperatively, we found Ulcer duodenal perforation and undertook the operation procedures by Roscoe Graham technique. Conclusions: At this age, it is rare, and it is difficult to detect in its early stages, because the signs and symptoms are often non-existent, non-specific, or mimic as an ulcer. The most common symptoms are early heartburn indigestion, abdominal pain or discomfort, vomiting, constipation, diarrhea or to feel of filling after a small meal, loss of appetite, weakness and fatigue. Less common symptoms are anemia and weight loss.

Keywords: Signet Ring Cell Type; Gastric Adenenocarcinoma; Diffuse Variant of GC

\section{INTRODUCTION}

Gastric Aden carcinoma is rare at young people, while the risk increases significantly after age 50, and gastric biopsies ambulatory ring cell carcinoma is rarely found due to atypical clinical presentation [2]. GCs are presented in different histological characteristics, with a positive family history, while genes regulate the sensitivity of Helicobacter Pylori at different types of CG [3]. Histological confirmation is very important for determining the method of treatment [4]. Signet ring cell carcinoma is characterized by sub-mucosal infiltration of different sizes and with distribution in distant lymph node, and metastasis in the skin $[5,6]$. Here we report the rare case of a 20 -year-old girl presented with acute abdomen, because of the perforated duodenal ulcer, with positive family history for GC and with Helicobacter Pylori positive. 


\section{PRESENTATION OF CASE}

We report one case of 20 years old patient (Kosovo, Albanian) with Signet Ring Cell Type of gastric CA. The patient was brought in emergency with severe abdominal pain, nausea, vomiting, pallor, and fatigue. The patient had a position with curved knees towards the stomach, hypertensive (TA: 100/60 $\mathrm{mmHg}$ ), pulse speed (110/min) and with superficial breathing. The clinical examination took place in emergency centre, which concludes: diffuse abdominal pain, irritation peritoneal signs. In X-ray native of abdomen are concluded signs of pneumoperitoneumit while in laboratory analysis are concluded the following values: $\mathrm{RBC}=3.69$; $\mathrm{RDW} \%=15.1$; $\mathrm{RDWA}=$ 32.1; $\mathrm{HCT}=\mathrm{L} 25.2 ; \mathrm{PLT}=\mathrm{H} 458 ; \mathrm{MPV}=\mathrm{L}$ 7.2; $\mathrm{PDW}=$ 9.7; $\mathrm{PCT}=0.33 ; \mathrm{LPCR}=9.7 ; \mathrm{WBC}=\mathrm{H} 18.4 ; \mathrm{HGB}=\mathrm{L}$ $88 \mathrm{HL} ; \mathrm{MCH}=\mathrm{L} 23.8 ; \mathrm{MCHC}=349 ; \mathrm{LYM}=0.9$; GRAN $=$ H 16.4; $\mathrm{MID}=1.1 ; \mathrm{LYM} \%=\mathrm{L} 5.3 ;$ GRA $\%=$ $\mathrm{H}$ 89.2; $\mathrm{MID} \%=5.5 ; \mathrm{Fe}^{2+}=4.31 \mu \mathrm{mol} / \mathrm{L}$. Glucose $=8.2$ $\mu \mathrm{mol} / \mathrm{L}$; Urea $=6.8 \mu \mathrm{mol} / \mathrm{L}$; Creatinine $8.5 \mu \mathrm{mol} / \mathrm{L}$; Total Bilirubin $=7.5 \mu \mathrm{mol} / \mathrm{L}$; Direct Bilirubin $=2.4 \mu \mathrm{mol} / \mathrm{L}$; $\mathrm{Na}^{+}=134 \mu \mathrm{mol} / \mathrm{L} ; \mathrm{K}^{+}=4.45 \mu \mathrm{mol} / \mathrm{L} ; \mathrm{Cl}^{-}=103 \mu \mathrm{mol} / \mathrm{L}$; $\mathrm{Ca}^{++}=1.23 \mu \mathrm{mol} / \mathrm{L} ;$ Albumins $=43 \mathrm{~g} / \mathrm{L} ; \mathrm{CRP}=5.7$ $\mathrm{mg} / \mathrm{L}$. Helicobacter Pylori $\mathrm{IgG}=$ positive (3.42) Blood type $=\mathrm{A}-\mathrm{RhD}(+)$ poz. The patient was hospitalized from emergency to the surgery department with diagnosis: acute abdomen, ulcer perforation. In the department we placed the wide nasogastric probe, and the compensation of the fluids parenteral were provided, blockers $\mathrm{H} 2$ histaminic and antibiotics. It is indicated the Surgical intervention, where the abdomen has been opened in layers through the median upper and middle laparotomy. Intra operative concludes: Serofibrinous fluid content and a hole that has penetrated to the wall of the front duodenum. It has been taken excision from the part of perforated duodenum for biopsy, and operation has been conducted by Roscoe Graham with omentoplasty. Washers

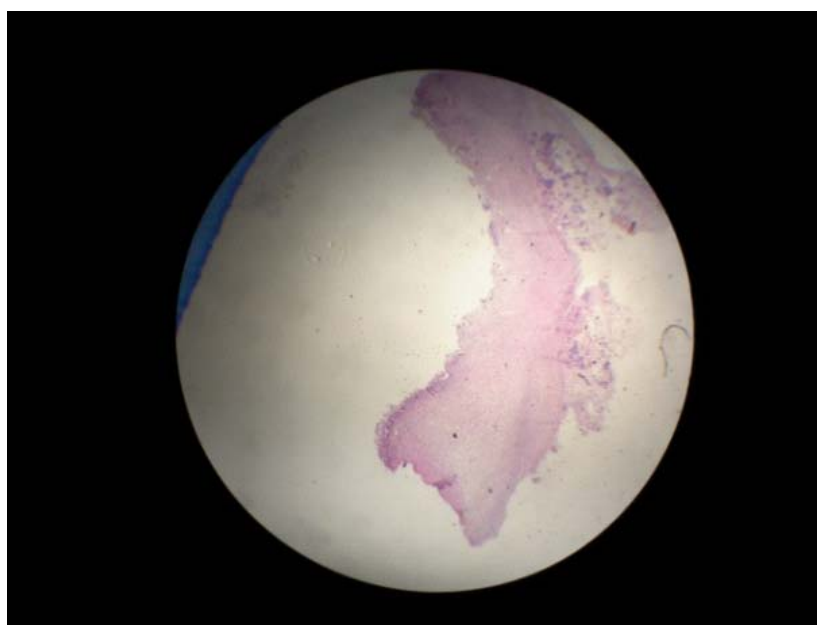

of peritoneal space and drainage of the Douglas space.

Postoperative, the patient stays in intensive care. Treated with intensive therapy: compensation of fluids, antibiotics, analgesic blockers, $\mathrm{H}_{2}$ Histaminic. Nasogastric tube and abdominal drain are removed in the fifth day after operation. Wound with no leaks. The patient has been recommended home care, in general stable condition. With therapy: oral antibiotics and oral protein pump inhibitors. The result of the biopsy of the excision of perforated place in the duodenum results as chronic peptic ulcer of the duodenum Figure 1.

10 days after discharge from the hospital, patient came back to Hospital In, while the patient continues to suffer the pain in the epigastria region, fatigue, and anorexia. The patient returns at home with therapy-analgesic as needed and protein pump inhibitors. After two weeks, the patient visited the surgeon again with the same symptoms (abdominal pain in the epigastria, nausea, vomiting, anorexia, fatigue). The surgeon suggested the patient to make the esophago gastro duodenoscopy, which resulted: hyperemia and non confluent longitudinal erosion of the bottom of stomach. In pre pyloric area of the stomach mucosa is edematous, infiltrated, and vulnerable. Infiltrate includes the pyloric canal which is narrow and is inaccessible by the instrument. From the infiltrated pre pyloric part is taken the biopsy in six parts for histopathological examination. Biopsy results: gastric carcinoma (Signet ring cell type) - infiltration into the pylorus with evident stenosis and Reflux esophagitis gr. A. (Figure 2).

Six days after verification of the diagnosis with histopathology, the patient was hospitalized at the American hospital in Prishtina. In the day of admission is done the CT of the abdomen and pelvic with application of instrument of the oral contrast and intravenous which resulted: expansive process in the rear wall of the small curvatures of the stomach and also pylorus have been affected, with characteristics of mucinous carcinoma,

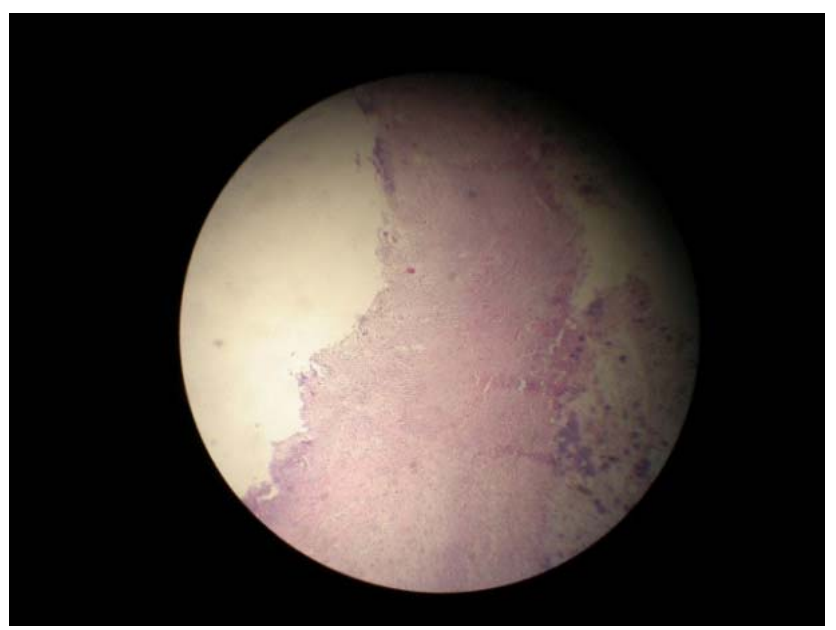

Figure 1. Histological report: ulcer peptic chronic duodenum (tissue granulation and peptic necrosis). 

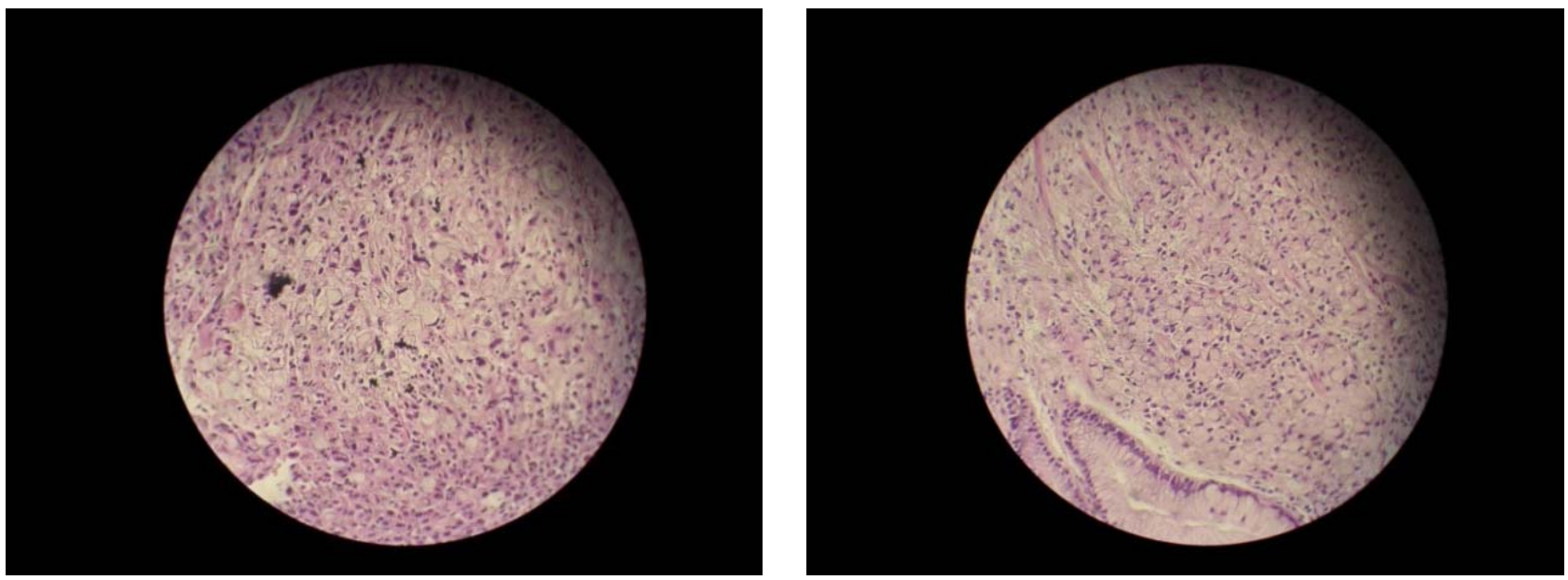

Figure 2. Histological report: ventricular carcinoma (signet ring cell type)—(fragments of gastric mucosa with solid islands malignnant stromal cells, polymorphous eccentric nuclei).

with gangrene of the gallblader.

On date: 23. 03. 2013 took place: op. Subtotal Gastrectomy D1 Lymph node disection, Gastroenterostomy, where more than $2 / 3$ of the stomach (pylorus, duodenum initial part) was removed and was established gastrointestinal continuity by direct anastomosis between the rest of the resected stomach and proximal anse of jejunum. Where initially gastro colic ligament is cut within gastroepiploic arcade, curvature ventricle major is released as long as the lower pole of the spleen is seen. Then resection duodenum is conducted about two $\mathrm{cm}$. from pylorus after resection of duodenum and the mobilization of the stomach. Stomach pulled above and now sinister gastric artery and vein are released which present resection line of curvature ventricle minor. It is set Gastrointestinal continuity in two layers, then occurs entero-entero-anastomosis according to Brown about $20 \mathrm{~cm}$ distally from gastrointestinal anastomosis with one layer. During surgical intervention in gastric tissues were identified lymph nodes as following (according to the classification of the Japanese Research Association for the classification of gastric cancer): Zone 1. (Right pericardial): 0 lymph nodes, Zone 2. (left pericardial): 0 lymph's nodes, Zone 3. (Curvature minor): 0 lymph's nodes, Zone 4. (Curvature major): 4 lymph nodes' measuring $0.2-0.6 \mathrm{~cm}$ in greatest diameter, Zone 5. (Supra pyloric): 0 lymph's nodes, Zone 6. (Infra pyloric): 9 lymph nodes measuring $0.2-1.2 \mathrm{~cm}$ in greatest diameter. Histological report resulted: Adenocarcinoma type Diffuse. Zone 4 (curvature major): Metastatic tumor tissue is identified in 1 lymph node (1/4). Zone 6 (infra pyloric) Metastatic tumor tissues is identified in 5 lymph nodes (5/9). Histological type: Adenocarcinoma-diffuse type. TNM pathological classification: $\mathrm{pT} 4 \mathrm{~b}, \mathrm{pN} 2, \mathrm{pM} 1$.

The postoperative is treated with antibiotic, analgesic, 4 doses blood and 3 plasma. On date 03. 04. 2013 rec- ommended going home, and visit the oncologist for further treatment. The patient has taken the therapy with chemotherapeutic.

\section{DISCUSSION}

Gastric carcinoma (GC) is more common in developing countries, among black peoples and in countries with poor socio-economic condition. Dietary factors and infection with Helicobacter pylori (H. pylori) are main risk factors for the development of such tumors [7]. H. pylori-stimulates cell polarity disorder that can be associated with the pathogenesis of carcinoma, at least in the layers of the population infected with HP [8]. Recently GC shows an EBV (+), in vitro EBV infection induces extensive mutation of the (ADN) DNA gene repression within 18 weeks, which can be considered another risk factor for the emergence of GC [9]. Gastric carcinoma of type (SRC) is known to have different characteristics and biological microscopic compared to non-(SRC) [5]. Our case has unusual clinical and histopathological manifestation that responds to data from the literature. On the basis of data protocol of our hospital was not evidenced so far any case with such type of CG under the age of 30 years. GC is one of the most common causes of cancer-related deaths worldwide. The success of surgery depends on the depth of penetration in layers, the extent of lymph node and distant metastases, and it is possible through diagnostic methods: MDCT (multi detector computed tomography) and PET (positron emission tomography). Multi detector computed tomography (MDCT) has the ability to assess the depth of the tumor, the main disease and metastasis so that preferred technique for managing GC. Endoscopic ultrasound is the most accurate assessment of the depth of wall invasion in early cancers, but is limited in the evaluation of stenosis or local advanced cancer and detection of distant metas- 
tases. Magnetic resonance imaging (MRI) has not proved to be effective. Positron emission tomography (PET) is useful for detection and characterization of distant metastases. Both MDCT and PET methods are useful for evaluating the response to treatment after chemotherapy, preoperative and detection of recurrence after surgical removal [10]. in our case was not possible to use diagnostic methods mentioned above, and because of the atypical clinical presentation, our case was diagnosed in the late stages of distant metastases, which represents an unfavorable prognostic factor. Rapid development of the tumor in our case, atypical clinical presentation and the increasing number of cancer in general, the experts suppose the risk factor comes from the high level of depleted uranium due to the recent war. SRC $\mathrm{Ca}$, do not have good prognosis and can be neglected during routine pathological examination [11]. For patient survival is important tumor localization, histopathological stages and treatment [12]. The following factors are also important for the patient survival: the extent of tumor in lymph nodes, depth of infiltration in layers and distant metastases [13]. SRC Ca survival depends on tumor size, histological cell differentiation level, the degree of penetration in layers and metastasis. 5-year survival after application of chemotherapy at patients with GC resectable is less than $20 \%$ and therefore the effectiveness of chemotherapy is disputed [14]. 5-year survival of the four groups classified by differentiation and depth of penetration in layers is [T2/3 (differentiated type), T2/3 (undifferentiated type), T4a (differentiated type), and T4a (undifferentiated type)] were $98 \%, 92 \%, 80 \%$, and $72 \%$, respectively $(\mathrm{P}<0.01)[15]$. Inhibitory effects on cell $\mathrm{Ca}$ growth of the stomach have antioxidant substances like: CFPS-2 containing: Glucosamin, glucose, Galactose, Fructose, protein and sulfate groups [16]. Our case is sent for chemotherapy treatment after consular decision and consultation with oncologist. Since about four months past after the first surgery and about three months after the second surgery, the general condition of the patient is stable.

\section{CONCLUSION}

Gastric Aden carcinoma in such age is rare, and it is difficult to detect it in its early stages, because the signs and symptoms are often non-existent, non-specific, or mimic as ulcer, therefore we recommends taking into consideration all patients complaints regardless of age and non-specific clinical data for malignant disease. The most common symptoms at the beginning are indigestion heartburn, abdominal pain or discomfort, vomiting, constipation, diarrhea, or a feeling of fullness after a small meal, loss of appetite, weakness and fatigue. Less common symptoms are anemia and weight loss. This case is presented because it is very rare at this age, and clinic atypical manifestation is in the form of perforated ulcers. It is the first reported case of this type of tumor for us, because of the very young age of the patient.

Patient Perspective: In order to provide data on the case, I report my concerns about the disease.

I am a second year student, living in the village, I have never been sick before. It has been about 3 months since I started to feel occasional pain in the stomach but no other concerns. At this time I used tablets to ease my pain, and I visited a general practitioner. I have thought the pain was coming from studies stress, but pain day by day hardened, when at hospital admission day at a time I felt severe abdominal unbearable pain, associated with nausea which forced me to go to the hospital. It was the first time that I had lay in the hospital, where I was undergoing urgent surgical intervention. After the operation I began to feel improvement and get sucked, even though after a week I continued to feel pain. A week after leaving the hospital I started the same concerns as before surgery such as stomach pain, loss of appetite and lassitude and I asked again for medical help from my surgeon who suggested me doing endoscopy of the stomach. After endoscopy my situation got worse and I have been hospitalized, where after a few days by the suggestion of doctors I have been transferred to American Hospital for second surgical intervention. It has been about 5 days since I left the hospital and I am waiting for further treatment. With the help of God and the support of family members, I want to fight for the life that I love it so much.

\section{CONSENT}

Written consent was obtained from our patient for the presentation of this case. A copy of the written consent is available for review by the editor of this magazine.

\section{REFERENCES}

[1] Liu, C. and Crawford, J. (2004) Gastric carcinoma. In Robins and Cotran, Eds., Pathologic Basis of Disease, 7th Edition, Elsevier \& Saunders, 822-827.

[2] Golembeski, C.P. and Genta, R.M. (2013) Signet-ring cell carcinoma in gastric biopsies: Expecting the unexpected. Journal of Clinical Pathology, 66, 136-139. doi:10.1136/jclinpath-2012-201102

[3] Ghoshal, U., Tripathi, S., Kumar, S., Mittal, B., Chourasia, D., Kumari, N., Krishnani, N. and Ghoshal, U.C. (2013) Genetic polymorphism of cytochrome P450 (CYP) 1A1, CYP1A2, and CYP2E1 genes modulate susceptibility to gastric cancer in patients with Helicobacter pylori infection. India Gastric Cancer.

[4] Kim, S.H., Lee, S.T., Jeon, B.J., Kim, I.H., Kim, S.W., Lee, S.O., Kim, D.G. and Park, H.S. (2012) Signet-ring cell carcinoma mimicking gastric gastrointestinal stromal tumor confirmed by endoscopic ultrasound-guided trucut 
biopsy. Clinical Endoscopy, 45, 421-424. doi:10.5946/ce.2012.45.4.421

[5] Huh, C.W., Jung da, H., Kim, J.H., Lee, Y.C., Kim, H., Kim, H., Yoon, S.O., Youn, Y.H., Park, H., Lee, S.I., Choi, S.H., Cheong, J.H. and Noh, S.H. (2013) Signet ring cell mixed histology may show more aggressive behavior than other histologies in early gastric cancer. Journal of Surgical Oncology, 107, 124-129. doi:10.1002/jso.23261

[6] Fekete, G.L., Cotoi, O.S. and Fekete, J.E. (2012) Multiple nodular cutaneous metastases as the first clinical sign of signet ring cell gastric carcinoma: Case report. Acta Dermatovenerologica Croatica, 20, 34-37.

[7] Siddavaram, N. (2012) Carcinoma of the stomach: A review of epidemiology, pathogenesis, molecular genetics and chemoprevention. World Journal of Gastrointestinal Oncology, 4, 156-169. doi:10.4251/wjgo.v4.i7.156

[8] Yonezawa, S., Kitajima, S., Higashi, M., Osako, M., Horinouchi, M., Yokoyama, S., Kitamoto, S., Yamada, N., Tamura, Y., Shimizu, T., Tabata, M. and Goto, M. (2012) A novel anti-MUC1 antibody against the MUC1 cytoplasmic tail domain: Use in sensitive identification of poorly differentiated cells in adenocarcinoma of the stomach. Gastric Cancer, 15, 370-381. doi:10.1007/s10120-011-0125-2

[9] Kaneda, A., Matsusaka, K., Aburatani, H. and Fukayama, M. (2012) Epstein-Barr virus infection as an epigenetic driver of tumorigenesis. Cancer Research, 72, 3445-3450. doi:10.1158/0008-5472.CAN-11-3919

[10] Hallinan, J.T. and Venkatesh, S.K. (2013) Gastric carcinoma: Imaging diagnosis, staging and assessment of treatment response. Cancer Imaging, 13, 212-227. doi:10.1102/1470-7330.2013.0023
[11] Osman, M.A., Bloom, G.S. and Tagoe, E.A. (2013) Helicobacter pylori-induced alteration of epithelial cell signaling and polarity as a possible mechanism of the etiology and disparity of gastric carcinoma. Cytoskeleton (Hoboken), 70, 349-359.

[12] Fatih, S., Evin, B., Deniz, T., Mustafa, O., Fuat, D. and Suheyla, S. (2013) Clinicopathological features and outcomes of patients with gastric cancer: A single-center experience. World Journal of Gastroenterology, 19, 21542161. doi:10.3748/wjg.v19.i14.2154

[13] Jiang, H., Zhang, H., Tian, L., Zhang, X. and Xue, Y. (2013) The difference in clinic-pathological features between signet ring cell carcinoma and gastric mucinous adenocarcinoma. Tumor Biology. doi:10.1007/s13277-013-0812-1

[14] Yamada, S., Ritchim, P., Charkrabandhu, T. and Jongraksat, W. (2012) Combination 5-fluoruracil/cisplatinum versus 5-fluoruracil/leucovorin adjuvant chemotherapy efficacy for R0 gastric resection in locally invasive gastric cancer. Journal of the Medical Association of Thailand, 95, 1517-1523.

[15] Liao, N., Chen, S., Ye, X., Zhong, J., Wu, N., Dong, S., Yang, B. and Liu, D. (2013) Antioxidant and anti-tumor activity of a polysaccharide from freshwater clam, Corbicula fluminea. Food \& Function, 4, 539-548. doi:10.1039/c2fo30178d

[16] Lee, I.S., Yook, J.H., Kim, T.H., Kim, H.S., Kim, K.C., Oh, S.T. and Kim, B.S. (2013) Prognostic factors and recurrence pattern in node-negative advanced gastric cancer. European Journal of Surgical Oncology, 39, 136-140. doi:10.1016/j.ejso.2012.10.008 